\title{
Application of a computer-based neurocognitive assessment battery in the elderly with and without hearing loss
}

This article was published in the following Dove Press journal:

Clinical Interventions in Aging

II October 2017

Number of times this article has been viewed

\section{Christiane Völter' \\ Lisa Götze' \\ Michael Falkenstein ${ }^{2}$ \\ Stefan Dazert' \\ Jan Peter Thomas'}

'Department of Otorhinolaryngology,

Head and Neck Surgery, Ruhr

University Bochum, St Elisabeth-

Hospital, Bochum, ${ }^{2}$ Institute for

Work, Learning and Ageing (ALA),

Leibniz Research Centre for Working

Environment and Human Factors,

Dortmund, Germany
Correspondence: Christiane Völter Department of Otorhinolaryngology, Head and Neck Surgery, Ruhr University Bochum, St Elisabeth-Hospital, Bleichstraße 15, 44787 Bochum,

Germany

Tel +492345098390

Fax +492345098391

Email christiane.voelter@ruhr-unibochum.de
Introduction: Due to demographic changes, the number of people suffering not only from dementia illness but also from hearing impairment with the need for hearing rehabilitation have increased noticeably. Even with the association between hearing, age, and cognitive decline being well known, this issue has so far not played an important role in daily clinical Ear Nose Throat settings. The aim of the present study was to evaluate the use of a computer-based battery of tests of neurocognitive abilities in older patients with and without hearing loss.

Patients and methods: A total of 120 patients aged 50 years and older were enrolled in this prospective clinical study: 40 patients suffered from severe bilateral hearing loss and were tested before cochlear implantation and 80 patients showed normal hearing thresholds between 500 and $4,000 \mathrm{~Hz}$ bilaterally. The test battery covered a wide range of cognitive abilities such as long- and short-term memory, working memory (WM), attention, inhibition, and other executive functions. Individuals with severe depression or cognitive impairment were excluded.

Results: Hearing status was a significant predictor of performance on delayed recall $(P=0.0082)$ and verbal fluency after adjusting for age $(P=0.0016)$. Age predominantly impacted on inhibition ( $P=0.0039)$ and processing speed $(P<0.0001)$, whereas WM measured by the Operation Span task (OSPAN) and the attention were influenced by both age and hearing. The battery of tests was feasible and practical for testing older patients without prior computer skills.

Conclusion: A computerized neurocognitive assessment battery may be a suitable tool for the elderly in clinical practice. While it cannot replace a thorough neuropsychological examination, it may help to draw the line between cognitive and hearing impairment in the elderly and enable the development of individual strategies for hearing rehabilitation.

Keywords: elderly, computer-based test battery, hearing loss, cognition

\section{Introduction}

Hearing impairment (HI) is the most common sensory decline with a growing incidence due to the increase of elderly people. ${ }^{1}$ Today $\sim 360$ million people are affected by a disabling hearing loss worldwide. Numerous sensory processes of the peripheral and central nervous system may present with structural and functional alterations. ${ }^{2,3} \mathrm{~A}$ longer duration of deafness leads not only to declines in dendritic and spiral ganglion cells and auditory nerve function but also to changes in plasticity and different central representations of phonemes at the level of the auditory cortex. ${ }^{4}$

With increasing age not only a sensory decline but also cognitive impairment becomes more apparent with $10 \%$ of men and women at the age of 65 years presenting with cognitive constraints. This rises up to $30 \%$ among people aged 80 years and older. . $^{5}$ 
An association between $\mathrm{HI}$ and cognitive decline has already been postulated. ${ }^{7}$ In a study including 639 subjects aged between 36 and 90 years, Lin et $\mathrm{al}^{74}$ showed that the risk of developing dementia within 10 years was twofold in those suffering from mild hearing loss and fivefold in people with a severe HI when compared with their normal hearing $(\mathrm{NH})$ counterparts. Also, the Maastricht Aging Study evaluating $>400$ participants over a 6-year follow-up revealed a correlation between cognitive abilities and sensory decline, showing that vision had an even greater impact on cognition than hearing. ${ }^{9}$ These relationships are so far not fully understood. Some suggest common underlying causes implying that diseases affecting the inner ear also have an impact on the brain. Others claim that the "cognitive load" caused by hearing difficulties leads to a mental decline. Social isolation resulting in a decrease in sensory stimulation has also been taken into consideration. ${ }^{10,11}$

Nowadays, aging is not perceived as cumbersome and unavoidable. Senior citizens emphasize a high level of social and cultural participation. ${ }^{12}$ Therefore, it is likely that elderly patients will visit their otolaryngologist for hearing amplification and restoration to an increasing extent in the future.

Cognitive assessment is not yet part of the audiological examination of adults in the otolaryngological setting, whereas for pediatrics, this is already done routinely. In contrast, in gerontopsychiatric departments dealing with individuals with known cognitive impairment such as minimal cerebral dysfunction and dementia hearing evaluation is rarely carried out. ${ }^{13}$ Nevertheless, a clear distinction between a cognitive and a hearing impairment might be challenging.

Commonly used cognitive assessment tools either are usually quite time-consuming or only provide a limited view of cognitive abilities. For example, the Consortium to Establish a Registry for Alzheimer's Disease neuropsychological battery (CERAD-NB) ${ }^{73}$ test is only available in paper and pencil and the Montreal Cognitive Assessment (MoCA) test lacks detailed information due to its purpose as a screening tool. ${ }^{14}$ Moreover, these test batteries rely on verbal instructions and an influence of hearing loss on diagnosis must be taken into consideration. ${ }^{15,16}$

A computer-based assessment of cognitive abilities may help the otolaryngologist or the rehabilitation specialist to better distinguish between hearing and cognitive impairment. Beside this, it may provide insight into what extent a restoration of the peripheral hearing disorder by surgical or nonsurgical options might help solve the communication problem of the patient.

The present study aims to evaluate the mental resources of patients aged 50 years and older with severe hearing loss and NH adults by applying a computer-based test battery covering different aspects of neurocognition.

\section{Patients and methods}

\section{Participants}

Patients aged 50 years or older attending the Department of Otorhinolaryngology, Head and Neck Surgery of the Ruhr University Bochum, Germany, between 2016 and 2017 were invited to participate in a prospective clinical study. All patients included either were native speakers or had advanced language skills due to living in Germany for $>20$ years. Individuals with severe visual impairment or with profound cognitive deficits as indicated by a general intelligence test were excluded. All eligible patients gave their written informed consent. The ethical institution of the Ruhr University Bochum approved the study (No 16-5727-BR).

\section{Neurocognitive testing}

At the Institute for Work, Learning and Aging (ALA), Dortmund, Germany, a multimodular database system was developed using the ALAcog Software to provide a computer-based test battery of different domains of cognition. A brief presession was included before the test battery. All instructions were visually presented.

The test battery was composed of eight different subtests, each covering a main aspect of neurocognitive abilities:

1. M3 (based on the $\mathrm{d} 2$ test of attention, Brickenkamp ${ }^{17}$ ): this test predominantly assesses attention. ${ }^{18}$ The letters $\mathrm{M}$ and $\mathrm{W}$, randomly accompanied by zero, one, two, or three dots, are shown on the screen, and participants are invited to respond only to the set stimulus ( $\mathrm{M}$ accompanied by three dots).

2. Recall (based on the verbal learning and memory test, Helmstaedter et $\mathrm{al}^{19}$ ): short-term memory is evaluated in combination with the delayed recall subtest. ${ }^{20}$ Within 90 seconds, 10 words are presented on the screen, which need to be memorized and recalled in writing.

3. Delayed recall: in this test, presented words need to be memorized and recalled after 30 minutes.

4. n-back (based on Kirchner ${ }^{21}$ and Wild-Wall et $\mathrm{al}^{22}$ ): according to Lezak, ${ }^{20}$ the n-back is commonly used for testing working memory (WM). The 2-back task relies on the presentation of letters for 4 minutes in total, each shown for 1.5 seconds. A reaction is required if the presented illuminated letter identically matches the letter shown second last. No reaction is needed for other stimuli. In the 0-back task, a response is only required if 
a specific predetermined letter is presented (a response is only required if the letter " $\mathrm{X}$ " is shown).

5. Flanker (based on Eriksen and Eriksen ${ }^{23}$ and Wild-Wall et $\mathrm{al}^{24}$ ): three overlying arrow head pointers are illuminated for a short time. The target pointer, the middle arrow, is flanked by nontarget stimuli pointing either in the same (compatible) direction or in the different (incompatible) direction. By focusing only on the middle target arrow, this task analyzes the ability to suppress irrelevant information. The participant is asked to respond to the direction of the pointer by pressing a specific key as fast as possible.

6. OSPAN (based on the "Operation Span task" ${ }^{25}$ ): according to Conway, ${ }^{26}$ this task also describes WM abilities. This dual task consists of two parts: patients have to tell whether a shown result of an equation is correct or not (first task) and at the same time recall an increasing number of single letters or numbers.

7. Trail tasks (based on Reitan ${ }^{27}$ ): the main cognitive abilities tested by the Trail A and Trail B refer, respectively, to processing speed and executive functions. ${ }^{28}$ Numbers from 1 to 26 appear in an unsystematic order on the screen and need ordering in an alternating way as fast as possible. Next, numbers and additional letters need to be ordered in the same way.

8. Verbal fluency (based on the "Chicago Word Fluency Test [CWFT]" Thurstone ${ }^{29}$ ): This test measures executive functions and long-term memory. ${ }^{20,30}$ This test requires the listing of as many animals as possible starting with a particular letter within 90 seconds.

In order to take into account the trade-off between speed and accuracy, a performance index (inverse efficiency) was calculated for each subtest and patient. ${ }^{22}$ Response time was divided by correct reactions, and higher values indicated poorer performance. Beside this, a detailed analysis of the raw data was conducted to obtain the reaction time, the number of correct or incorrect, as well as compatible or incompatible stimuli.

\section{Questionnaires}

General crystallized intelligence was assessed with the Mehrfachwahl-Wortschatz-Intelligenz test (MWT-B). ${ }^{31}$ This test contains a list of 37 lines, each line including four fictional words and one real-word of increasing difficulty. Patients are asked to identify the real-word in each line. Additionally, a questionnaire was designed to evaluate the subjective usability of the computer-based test battery and subjects were asked to rate their computer skills for practical purpose on a visual analog scale from 1 to $10(1=$ no skills and $10=$ professional skills). Comorbidities and educational background were also questioned.

\section{Audiometric evaluation}

All tests were assessed in a sound booth (DIN EN ISO 8253) at the Department of Otorhinolaryngology of the Ruhr University Bochum, Germany. Pure tone air conduction audiometry was performed at the frequencies $0.5,1,2$, and $4 \mathrm{kHz}$. According to the World Health Organization, NH is defined as a 4-frequency pure tone average (4-PTA) of $\leq 25 \mathrm{~dB}$. In HI subjects, speech comprehension testing was conducted using the German Freiburger monosyllabic word test at 65 and $80 \mathrm{~dB}$ sound pressure level in the unaided and best-aided conditions.

\section{Statistical analysis}

Patient's characteristics were presented as mean data with SD. Differences in computer skills and hearing abilities were analyzed using Mann-Whitney $U$-tests. The sex distribution between study groups was compared using a chi-square test. Differences between study groups on each subtest of the computer-based test battery were initially explored using Mann-Whitney $U$-tests. Next, multiple regression was used to analyze the relationship between hearing status, age (continuous), sex, and each neurocognitive subtest. All results were interpreted at a significance level of 0.05 . Data analysis was performed using Medas (Grund Company, Wuerzburg, Germany).

\section{Results \\ Participants}

In total, 132 participants were enrolled in the study. Twelve participants were excluded due to language difficulties $(n=5)$, known severe cognitive impairments with an IQ of $<88$ $(n=5)$, a lack of motivation $(n=1)$, or a psychiatric disease (Geriatric Depression Scale $>5)(n=1) .{ }^{32}$ Data collection and analysis was carried out with 120 patients: 40 individuals with a severe to profound sensorineural hearing loss (34\%) and $80 \mathrm{NH}$ controls (66\%). All these patients showed normal intelligence according to the MWT-B and had good oral and nonoral language skills.

Patients were aged between 50 and 90 years with an average of $65.8( \pm 8.9)$ years. A total of $59(49 \%)$ individuals were younger than 65 years, whereas $61(51 \%)$ individuals were 65 years and older (Figure 1). There were 56 (47\%) males and $64(53 \%)$ females in total: 31 males and 28 females were younger than 65 years and 25 males and 36 females were older than 65 years. There were no significant differences 


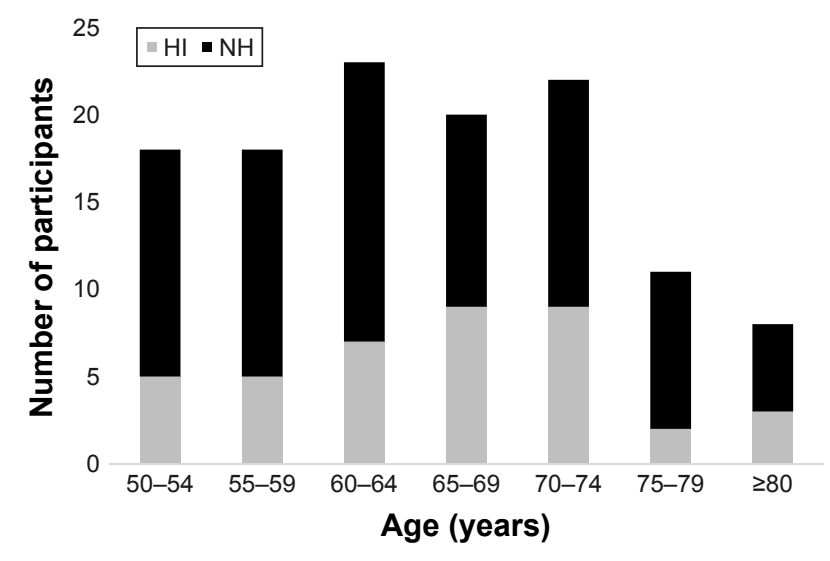

Figure I Demographic data.

Note: Number of participants with hearing impairment $(\mathrm{HI})$ and normal hearing $(\mathrm{NH})$ according to age (years).

Abbreviations: $\mathrm{HI}$, hearing impairment; $\mathrm{NH}$, normal hearing.

between NH and HI subjects in age $(P=0.27)$ and $\operatorname{sex}(P=0.95)$. Patient characteristics are summarized in Table 1.

\section{Hearing levels}

Participants classified as having NH with a 4-PTA of 16 $( \pm 5.7) \mathrm{dB}$ in the better ear and $21( \pm 7.3) \mathrm{dB}$ in the other ear. $\mathrm{HI}$ individuals showed a 4-PTA of $80( \pm 18.9) \mathrm{dB}$ in the better ear and $101( \pm 9.8) \mathrm{dB}$ in the other ear (Figure 2). Without a hearing aid, the mean speech perception was $6 \%$ at $65 \mathrm{~dB}$, increasing to $35 \%$ at $80 \mathrm{~dB}$. In the aided condition with a hearing aid, subjects reached a mean speech comprehension of $45 \%$ at $65 \mathrm{~dB}$ and $60 \%$ at $80 \mathrm{~dB}$.

\section{Self-rated computer experience}

Participants showed an intelligence quotient of 107 on average, with a mean score of $29.71( \pm 3.7)$ points on the MWTB. The mean time to complete the presession was $\sim 34.9$ $( \pm 15.3)$ minutes, and the test itself required 40 minutes. The NH subjects spent $29.6( \pm 10.5)$ minutes on the pretest, and the HI subjects spent $45.5( \pm 17.9)$ minutes on the pretest. On average, self-rated computer experiences were rated 6.0. Elderly people $\geq 65$ years were less skilled (4.9 $[ \pm 3.4])$

Table I Patient's profile

\begin{tabular}{lll}
\hline Characteristics & NH & HI \\
\hline Age (years) & $65.6(9.4)$ & $65.8(7.9)$ \\
Sex & Male $=37$ & Male $=19$ \\
& Female $=43$ & Female $=2$ I \\
4-PTA on better ear (dB) & $16(5.7)$ & $80(18.9)$ \\
Educational background (years) & $12.5(1.9)$ & $13.3(2.3)$ \\
^Self-rated computer experience & $6.0(3.1)$ & $5.9(3.4)$ \\
\hline
\end{tabular}

Notes: Data presented as mean (SD). ${ }^{\wedge}$ The self-rated computer experience was obtained on a visual analogue scale ( $\mathrm{I}=$ no experience, $\mathrm{I} 0=$ very good experience). Abbreviations: $\mathrm{HI}$, hearing impairment; $\mathrm{NH}$, normal hearing; 4-PTA, 4-frequency pure tone average. than younger adults $(7.0[ \pm 2.5])(P=0.00066)$. There was, however, no significant difference between subjects with $\mathrm{HI}$ $(5.9[ \pm 3.4])$ and $\mathrm{NH}(6.0[ \pm 3.1])(P=0.9)$.

\section{Associations between hearing, age, sex, and cognitive performance}

Association between hearing abilities and cognition

When looking at inverse efficiency, differences in cognitive skills depending on hearing status were observed on most of the subtests (Table 2).

The HI subjects presented with a highly significant deficit in verbal fluency where $\mathrm{NH}$ individuals named on average $1.7( \pm 2.8)$ animals more than their HI counterparts $(\mathrm{HI}=6.2$ $[ \pm 2.6] ; \mathrm{NH}=7.9[ \pm 2.8], P<0.00034)$. Significant differences between hearing status were observed on the recall test ( $P=0.025)$, the delayed recall $(P=0.0039)$, and the $n$-back test $(P=0.0085)$. No significant differences were found between the NH and the HI on the M3, flanker, OSPAN, and the Trail $\mathrm{A}$ and $\mathrm{B}$ tests (Figure 3).

The raw data revealed that hearing loss had a significant influence on reaction time in some neurocognitive subtests, namely the M3 and the n-back, and on the number of correct answers on the OSPAN and Flanker tests.

The number of errors and the reaction time differed between the $\mathrm{NH}$ and the $\mathrm{HI}$ subjects on the M3 $(P=0.01$ for errors and $P=0.046$ for reaction time) and the 2-back and 0-back tasks. Having a hearing loss significantly extended the reaction time ( $P=0.027)$, increased the number of missed letters $(P=0.054)$, and reduced the number of correct letters $(P=0.049)$ on the 2-back task, whereas there were no significant differences between groups in reaction time $(P=0.35)$, the number of correct letters ( $P=0.62)$, and missed letters $(P=0.78)$ on the 0 -back test.

The inhibition test revealed significant differences between $\mathrm{NH}$ and $\mathrm{HI}$ individuals in the number of correct incompatible stimuli $(P=0.027)$ but not in reaction time $(P=0.49)$.

On the OSPAN subtest, differences in reaction time between groups were not significant, whereas hearing ability leads to significant differences in the amount of recalled numbers and letters $(P=0.003)$.

\section{Association between age and cognition}

Comparing performance between age groups also revealed differences in cognitive skills. Table 3 shows older adults to perform relatively worse than younger adults on all subtests, except recall and verbal fluency. Differences between age groups were significant on the M3 $(P=0.0000)$, the Flanker $(P=0.011)$, the Trail A $(P=0.0000)$ and Trail B $(P=0.00054)$, the n-back $(P=0.012)$, and the OSPAN task $(P=0.0031)$. 


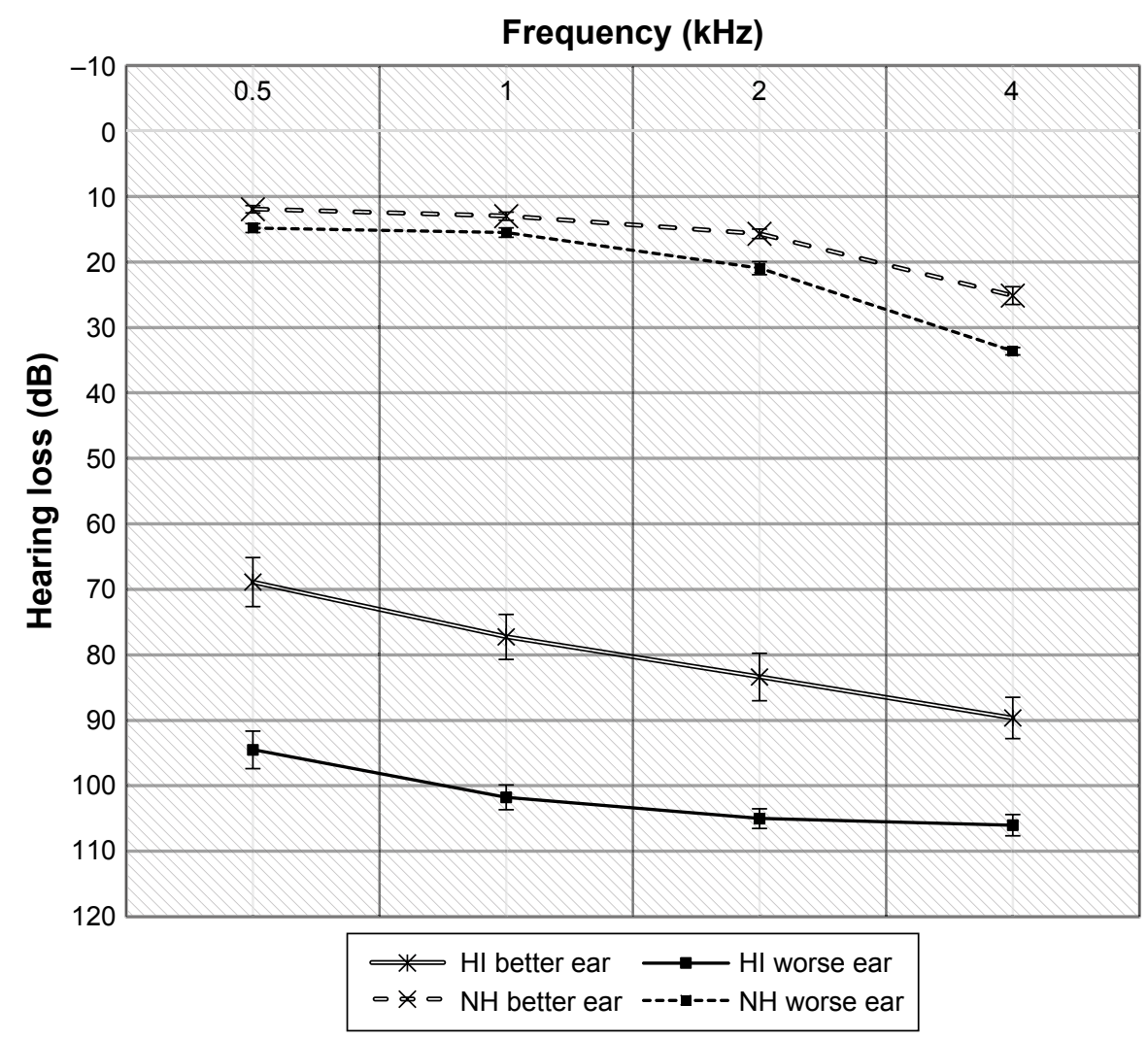

Figure 2 Mean air conduction thresholds for $\mathrm{NH}$ and $\mathrm{HI}$ subjects.

Note: Whiskers show the standard deviation of the mean.

Abbreviations: $\mathrm{HI}$, hearing impairment; $\mathrm{NH}$, normal hearing.

The role of hearing status and age on cognition

Hearing status and age were important predictors of cognitive skills on the M3 and OSPAN subtests; the impact of sex was only observed on the verbal fluency test. The results from multiple regression analyses after adjusting for hearing, age, and sex are summarized in Table 4.

Although hearing status was a significant predictor of performance, aging was the strongest predictor of M3

Table 2 Results (inverse efficiency) obtained on the different neurocognitive subtests in $\mathrm{NH}$ and $\mathrm{HI}$ participants

\begin{tabular}{llll}
\hline Subtest & NH, mean (SD) & HI, mean (SD) & P-value \\
\hline M3 & $823.737(276.788)$ & $952.425(373.668)$ & 0.078 \\
Recall & $443.500(183.545)$ & $508.250(215.976)$ & $0.025^{*}$ \\
Delayed recall & $573.500(205.563)$ & $684.750(219.416)$ & $0.0039^{*}$ \\
n-back & $163.286(120.116)$ & $203.600(92.8 I I)$ & $0.0085^{*}$ \\
Flanker & $145.859(156.920)$ & $153.697(131.269)$ & 0.36 \\
OSPAN & $492.188(232.461)$ & $633.125(384.402)$ & 0.078 \\
Trail A & $672.075(220.769)$ & $687.950(200.083)$ & 0.56 \\
Trail B & $597.037(273.211)$ & $596.475(289.120)$ & 0.96 \\
Verbal fluency & $760.625(83.826)$ & $815.125(81.276)$ & $0.00034^{*}$ \\
\hline
\end{tabular}

Note: $* P<0.05$.

Abbreviations: $\mathrm{HI}$, hearing impairment; $\mathrm{NH}$, normal hearing; OSPAN, Operation Span task. performance. Age was also a significant predictor of performance on the OSPAN test; however, hearing was the strongest predictor. Hearing status was a strong, but not a significant predictor on the n-back, whereas age was a significant one.

Hearing status was the strongest predictor of performance on the recall and delayed recall subtest, whereas sex and age were not predictors. Hearing status and sex were significant predictors of verbal fluency after adjusting for the effect of age.

Hearing status was not a predictor of performance on the inhibition test, but age itself was a significant predictor. Multiple regression for Trail A and Trail B revealed age to be a significant predictor after adjusting for hearing and sex, whereas the effect of sex and hearing was not significant.

\section{Questionnaires}

After completion of the test battery, $91 \%$ of all participants indicated a preference for the computer-based test rather than a paper-pencil version and the vast majority (94\%) found the instructions to be simple. Despite no significant differences in preferences between age groups or $\mathrm{NH}$ and $\mathrm{HI}$ groups, 


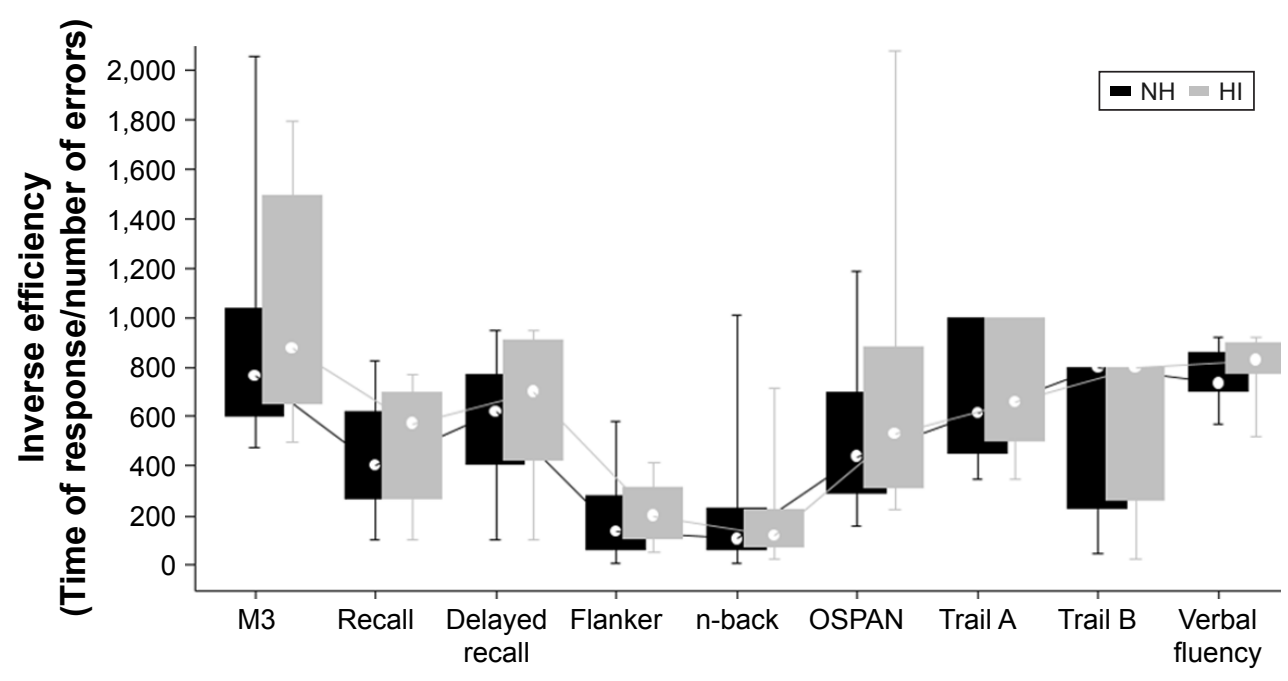

Subtests

Figure 3 Results obtained on the different neurocognitive subtests.

Note: Boxes contain $68 \%$ of the patients, dots within the boxes represent the median, and the whiskers show the span of data for the $\mathrm{NH}$ and $\mathrm{HI}$ participants.

Abbreviations: $\mathrm{HI}$, hearing impairment; $\mathrm{NH}$, normal hearing; OSPAN, Operation Span task.

the time required to complete the test was different: 16 $( \pm 17.9)$ minutes more were needed in the HI $(P<0.000005)$ and $9( \pm 10.4)$ minutes more in the elderly $(P=0.00035)$. Prior to testing, $44 \%$ of the HI subjects and $38 \%$ of the $\mathrm{NH}$ subjects were concerned about the implementation of the test. Afterward, $69 \%$ of all rated the test to be demanding, but $94 \%$ claimed that the test was fun and the length was adequate $(70 \%)$. Especially elderly participants presented highly self-confident, with $88 \%$ postulating that this assessment is suitable for participants of all ages in contrast to $72 \%$ of the younger adults.

\section{Discussion}

Initial research in the field of speech comprehension mainly focused on the peripheral auditory pathway, the so-called bottom-up spectrotemporal details of speech. ${ }^{3}$ Increasing evidence over the last years indicates that listening also

Table 3 Results (inverse efficiency) obtained on the different neurocognitive subtests in association to age

\begin{tabular}{llll}
\hline Subtest & $\begin{array}{l}<6 \text { years, } \\
\text { mean (SD) }\end{array}$ & $\begin{array}{l}>\text { 65 years, } \\
\text { mean (SD) }\end{array}$ & P-value \\
\hline M3 & $754.915(271.952)$ & $974.689(321.487)$ & $0.0000^{*}$ \\
Recall & $464.068(200.044)$ & $466.066(194.562)$ & 0.98 \\
Delayed recall & $592.034(207.512)$ & $628.525(223.918)$ & 0.35 \\
n-Back & $160.526(131.065)$ & $192.783(90.466)$ & $0.012^{*}$ \\
Flanker & $118.607(104.368)$ & $178.309(180.066)$ & $0.01 I^{*}$ \\
OSPAN & $470.136(242.444)$ & $605.934(331.644)$ & $0.003 I^{*}$ \\
Trail A & $565.424(149.663)$ & $785.639(210.746)$ & $0.00000^{*}$ \\
Trail B & $507.661(304.438)$ & $683.115(218.253)$ & $0.00054^{*}$ \\
Verbal fluency & $776.017(78.057)$ & $78 I .475(94.663)$ & 0.65 \\
\hline Note: $* P<0.05$. & & & \\
Abbreviation: OSPAN, Operation Span task.
\end{tabular}

requires the contribution of top-down mechanisms of stimulus interpretation ${ }^{33,34}$ and linguistic knowledge such as phonological, semantic, lexical, and contextual knowledge, as well as grammatical skills. ${ }^{3}$ The overall control of these

Table 4 Results of the multiple regression analyses

\begin{tabular}{|c|c|c|c|c|}
\hline Subtest & Predictor & $P$-value & Beta-weight (SD) & B-weight \\
\hline \multirow[t]{3}{*}{ M3 } & Age & $<0.000 I^{*}$ & 0.4 II 7 (0.083) & 14.72 \\
\hline & Hearing & $0.029 *$ & $0.181(0.082)$ & 121.558 \\
\hline & Sex & 0.72 & $0.0295(0.083)$ & 18.639 \\
\hline \multirow[t]{3}{*}{ Recall } & Hearing & 0.091 & $0.1547(0.091)$ & 64.202 \\
\hline & Sex & 0.12 & $-0.1437(0.091)$ & -56.33 \\
\hline & Age & 0.93 & $-0.0085(0.09 \mathrm{I})$ & -0.189 \\
\hline \multirow[t]{3}{*}{ Delayed recall } & Hearing & $0.0082 *$ & $0.2402(0.089)$ & 109.532 \\
\hline & Sex & 0.17 & $-0.1249(0.09)$ & -53.842 \\
\hline & Age & 0.56 & $0.052(0.09)$ & 1.267 \\
\hline \multirow[t]{3}{*}{ n-Back } & Age & $0.017^{*}$ & $0.2181(0.09)$ & 2.743 \\
\hline & Hearing & 0.078 & $0.1592(0.089)$ & 37.434 \\
\hline & Sex & 0.69 & $-0.0365(0.09)$ & -8.105 \\
\hline \multirow[t]{3}{*}{ Flanker } & Age & $0.0039 *$ & $0.2658(0.09)$ & 4.307 \\
\hline & Sex & 0.84 & $-0.0181(0.09)$ & -5.192 \\
\hline & Hearing & 0.91 & $0.0106(0.09)$ & 3.199 \\
\hline \multirow[t]{3}{*}{ OSPAN } & Hearing & $0.017^{*}$ & $0.2156(0.089)$ & I35.584 \\
\hline & Age & $0.035^{*}$ & $0.1912(0.089)$ & 6.434 \\
\hline & Sex & 0.94 & $-0.0065(0.089)$ & -3.874 \\
\hline \multirow[t]{3}{*}{ Trail A } & Age & $<0.000 I^{*}$ & $0.546 \mathrm{I}(0.079)$ & 13.163 \\
\hline & Sex & 0.61 & $-0.0399(0.078)$ & -16.987 \\
\hline & Hearing & 0.89 & $0.0107(0.078)$ & 4.809 \\
\hline \multirow[t]{3}{*}{ Trail B } & Age & $<0.000$ I* & $0.373(0.087)$ & 11.688 \\
\hline & Hearing & 0.84 & $-0.0175(0.086)$ & -10.235 \\
\hline & Sex & 0.95 & -0.005 I (0.087) & -2.826 \\
\hline \multirow[t]{3}{*}{ Verbal fluency } & Hearing & $0.0016^{*}$ & $0.2818(0.087)$ & 51.468 \\
\hline & Sex & $0.037^{*}$ & $-0.186(0.088)$ & -32.104 \\
\hline & Age & 0.85 & $0.0162(0.088)$ & 0.159 \\
\hline
\end{tabular}

Note: $* P<0.05$

Abbreviation: OSPAN, Operation Span task. 
neurocognitive processes is provided by executive functions including inhibition, cognitive flexibility, and WM. ${ }^{35}$ In contrast to short-term memory, which only stores information, WM enables a processing of the incoming signal. It comprises verbal, numerical, and visuospatial processing of information and is therefore also associated with executive functions. ${ }^{36}$

In adverse listening conditions such as fluctuating background noise and competing speakers, top-down processes play an even more important role. As implemented in Ronnberg's model of "Ease of Language Understanding" (ELU), the mismatch between the phonological input and the semantic information stored in the long-term memory requires a cognitive support for encoding the incoming signal. ${ }^{37}$ The type of top-down constraints depends not only on the individual listener's hearing and cognitive abilities but also on the type of speech processing.

Top-down mechanisms become even more important in older listeners than in younger subjects. Cognitive spare capacity is not reduced in the elderly when listening conditions are optimal but may decrease significantly in noise as demonstrated by Mishra et al. ${ }^{38}$ Meister et al revealed that on tasks of divided attention, older adults aged on average 68 years performed poorer than younger adults aged on average 24 years. On tasks of selective attention, speech comprehension was strongly related to WM skills. ${ }^{39}$

The most important cognitive domain involved in speech comprehension is the WM capacity. ${ }^{40}$ As shown by WildWall et $\mathrm{al}^{22}$ and Dobbs and Rule, ${ }^{41}$ chronological age has a great influence on WM. In challenging listening situations, older NH listeners rely more on their WM compared to younger individuals. ${ }^{39}$ In contrast, participants with relevant hearing loss are more vulnerable to age-related decline in WM. ${ }^{42}$ In our study, the OSPAN and the n-back task, commonly used tests for assessing WM, were significantly influenced by age and hearing. The small differences between the two tests might be due to the retrieval process of the target, either recall or recognition, as stated by Redick and Lindsey. ${ }^{43}$

Besides WM, processing speed measured in the present study with the Trail A and M3 tests is another relevant top-down determinant of speech comprehension. Analyzing this attention-related task revealed a highly significant agedependent effect in our study. These results support the idea of declining attention predominantly caused by age. ${ }^{44}$ It might also be due to the test setting in the presented study. The HI might have been able to compensate for age differences at the beginning of the test battery on the M3 test, whereas this might have not been the case toward the end.
Inhibitory abilities, another important domain of executive functions, were significantly influenced by age on the Flanker test. While hearing status was not a significant predictor of the IE performance, some differences were observed. Overall, participants with a hearing loss presented with a slower reaction time and $50 \%$ of reduced accuracy compared to NH controls.

The results of the Trail tests relied strongly on age but not on hearing capacity. In contrast to our results, Ellis et $\mathrm{al}^{45}$ described a correlation between speech understanding in noise and the Trail making test. Age-related decline in motor skills may have influenced this result as this test was strongly dependent on the ability to use a mouse.

Hearing ability had an impact on other subtests. The strongest influence of hearing ability on cognitive skills was observed on the verbal fluency task. NH participants recalled 1.7 more correct words than the HI participants. In line with our results, the Maastricht Aging Study also described hearing aid fitting to have a relatively large impact on verbal fluency and recall tasks. ${ }^{9}$ This might be due to the fact that transferring information to the WM requires phonological recall, which may be altered by auditory deprivation in individuals with hearing loss. ${ }^{46}$ In such individuals, good WM can compensate for the negative impact of auditory deprivation on phonological processing abilities. ${ }^{47}$

The verbal fluency test used in this study consisted of a combination of semantic and letter fluency tasks (eg, asking the participant to name animals starting with B); therefore, it assessed not only WM but also long-term memory. The results are in line with Lin et $\mathrm{al}^{8}$ and Rudner et $\mathrm{al}^{48}$ who described poorer long-term memory capability in older adults suffering from severe hearing loss. Long-term memory function may decrease as a result of insufficient use over an extended period of time; in the elderly, this may be due to the ongoing mismatch occurring regularly under adverse hearing situations. ${ }^{47}$

Additionally, an association between sex and the verbal fluency test was observed: women performed significantly better than men as in accordance with Weiss et al. ${ }^{49}$ Sex differences in cognitive abilities are well described in the literature with women outperforming men in regard to verbal abilities but showing visuospatial disadvantages. ${ }^{50}$ Along with that, men are more prone to suffer from a hearing loss than women and display a faster rate of progression. ${ }^{51,52}$

Not only verbal recall but also memory tests underline the reduction in short-term memory in the HI. ${ }^{53,54} \mathrm{NH}$ controls were significantly better in recalling words shortly after their presentation, as well as after some time, although they were only visually presented. Verhaegen et $\mathrm{al}^{55}$ identified 
reduced hearing levels as an important factor in explaining poor auditory verbal short-term memory performance in older adults.

These memory tasks, which are often components of standardized cognitive test batteries in face-to-face interviews, are vulnerable to the influence of hearing loss. Jorgensen et $\mathrm{al}^{16}$ demonstrated in a cohort of 125 young individuals that a simulated hearing loss led to the false diagnosis of cognitive impairment in healthy subjects. This observation is in alignment with Moafmashhadi who used the MoCA test battery in individuals with visual or HI. ${ }^{56}$

Thereby, computer-based assessment might be a more reliable way to study the HI. The influence of computer skills on the results should however not be forgotten, even though studies have shown the equality of paper-pencil and computer-based tests. ${ }^{57,58}$ Beside this, self-efficacy as measured in our study seems much more important. ${ }^{59}$ Thus, the application of a trial test allowing patients to gain familiarity with the computer under supervision might be helpful.

In this study, participants were matched on age and sex; however, other factors that may have an influence on test performance cannot be completely ruled out. Socioeconomic differences, the effect of daily cognitive demand due to profession or hobbies, as well as physical engagement may also contribute to cognitive decline. Furthermore, reading abilities may also influence differential performance. These factors should be assessed in future research.

Regardless of the abovementioned limitations, the presented study clearly demonstrated that chronological age and hearing ability together can have a strong influence on neurocognitive domains. Tasks that rely on the phonological loop strongly interacted with hearing, whereas tasks covering the executive functions such as inhibition, cognitive flexibility, and attention were highly dependent on age. As the described subtests measure not only a single part of cognition, an overlap of different aspects cannot be avoided. ${ }^{47,60}$

Many studies have been published reporting the effects of hearing aid use on cognition. ${ }^{61,62}$ So far, the results are quite conflicting. Castiglione et $\mathrm{al}^{63}$ demonstrated that aural rehabilitation with hearing aids improved performance on short- and long-term memory tasks as well as depression levels and cognitive status; other researchers have shown contradictory results. ${ }^{64-66}$

Besides the impact of conventional hearing aids, two recent publications have evaluated cognitive changes after cochlear implantation. In a prospective study covering a period of 2-4 years, seven females aged on average 74 years were assessed on five different domains. While verbal functions, memory and processing speed tested by the animal test, and the list recall showed improvements, motor functions and processing speed measured by Trail tasks declined after implantation. ${ }^{67}$

In another study, Mosnier et $\mathrm{al}^{68}$ evaluated 94 elderly participants before and 12 months after cochlear implantation and observed verbal fluency to be the strongest predictor of speech perception in noise. Interestingly, cognition improved especially in individuals with poor baseline results, while it remained stable in individuals with better preoperative scores. Attention and executive functions showed a postoperative amelioration as assessed by the Mini-Mental State Examination. This may be explained by a decreasing cognitive load following hearing restoration.

In the future, top-down mechanisms might be addressed more in hearing rehabilitation, which is so far mainly based on pure aural training of the bottom-up processes. ${ }^{69}$ Studies using a cognitive auditory-based training program have claimed significant improvements in auditory short-term memory, auditory and visual sustained attention, processing speed, as well as speech perception in noise. ${ }^{70}$ Ferguson and Henshaw $^{71,72}$ indicated that a combined cognitive and auditory training program is the most promising approach, offering generalized benefits for everyday life in HI people.

Precise knowledge about the neurocognitive profile of a subject might help to adapt rehabilitation programs to individual requirements. A nonphonological approach focusing on memory encoding could be utilized in the HI with low WM capacity. ${ }^{47}$ Patients suffering from attentional problems may benefit from short training sessions, whereas others with prolonged processing speech will need more time in individual settings.

The growing number of people with dementia raises the need for a feasible assessment tool to help distinguish between $\mathrm{HI}$ and cognitive decline. The present study revealed that a computer-based test battery may be adequate for the elderly. Due to the high standardization of the stimulus presentation, the feasibility of the analysis, and its practicability, the presented test battery represents a suitable tool for routine clinical practice. Even though it cannot replace the complex and subtle diagnosis that a neuropsychologist can provide, it can be valuable in aiding the otolaryngologist to determine the best hearing rehabilitation strategy particularly for the elderly.

\section{Acknowledgment}

We are grateful to Dr Imme R Haubitz for statistical support, Melodi Kosaner Kliess (MED-EL) for language editing on 
a version of this manuscript, and Ludger Blanke (Leibniz Research Centre for Working Environment and Human Factors) for helpful technical assistance.

\section{Disclosure}

The authors report no conflicts of interest in this work.

\section{References}

1. Mathers C, Smith A, Concha M. Global Burden of Hearing Loss in the Year 2000. Available from: https://pdfs.semanticscholar.org/72a0/ 9591b7a97c862224c06a2e32f27419a781f6.pdf. Accessed July 23, 2017.

2. Tremblay KL, Backer KC. Listening and learning: cognitive contributions to the rehabilitation of older adults with and without audiometrically defined hearing loss. Ear Hear. 2016;37(suppl 1): $155 \mathrm{~S}-162 \mathrm{~S}$.

3. Moberly AC, Bates C, Harris MS, Pisoni DB. The enigma of poor performance by adults with cochlear implants. Otol Neurotol. 2016;37(10): $1522-1528$.

4. Peelle JE, Wingfield A. The neural consequences of age-related hearing loss. Trends Neurosci. 2016;39(7):486-497.

5. Ferri CP, Prince M, Brayne C, et al. Alzheimer's Disease International. Global prevalence of dementia: A Delphi consensus study. Lancet. 2005;366(9503):2112-2117.

6. Bernabei R, Bonuccelli U, Maggi S, et al. Participants in the Workshop on Hearing Loss and Cognitive Decline in Older Adults. Hearing loss and cognitive decline in older adults: questions and answers. Aging Clin Exp Res. 2014;26(6):567-573.

7. Uhlmann RF, Larson EB, Rees TS, Koepsell TD, Duckert LG. Relationship of hearing impairment to dementia and cognitive dysfunction in older adults. JAMA. 1989;261(13):1916-1919.

8. Lin FR, Ferrucci L, Metter EJ, An Y, Zonderman AB, Resnick SM. Hearing loss and cognition in the Baltimore longitudinal study of aging. Neuropsychology. 2011;25(6):763-770.

9. Valentijn SAM, van Boxtel MPJ, van Hooren SAH, et al. Change in sensory functioning predicts change in cognitive functioning: results from a 6-year follow-up in the maastricht aging study. J Am Geriatr Soc. 2005;53(3):374-380.

10. Roberts KL, Allen HA. Perception and cognition in the ageing brain: a brief review of the short- and long-term links between perceptual and cognitive decline. Front Aging Neurosci. 2016;8:39.

11. Fortunato S, Forli F, Guglielmi V, et al. A review of new insights on the association between hearing loss and cognitive decline in ageing. Acta Otorhinolaryngol Ital. 2016;36(3):155-166.

12. Statistisches Bundesamt W. Die Generation $65+$ in Deutschland: Anlässlich der Pressekonferenz des Statistischen Bundesamtes am 29. Juli 2015; 2015. Available from: https://www.destatis.de/DE/ PresseService/Presse/Pressekonferenzen/2015/generation65/Pressebroschuere_generation65.pdf?_blob=publicationFile. Accessed July 23, 2017.

13. Jorgensen LE, Palmer CV, Fischer G. Evaluation of hearing status at the time of dementia diagnosis. Audiol Today. 2014;26:38-45.

14. Nasreddine ZS, Phillips NA, Bedirian V, et al. The Montreal Cognitive Assessment, MoCA: a brief screening tool for mild cognitive impairment. J Am Geriatr Soc. 2005;53(4):695-699.

15. Dupuis K, Pichora-Fuller MK, Chasteen AL, Marchuk V, Singh G, Smith SL. Effects of hearing and vision impairments on the Montreal Cognitive Assessment. Neuropsychol Dev Cogn B Aging Neuropsychol Cogn. 2015;22(4):413-437.

16. Jorgensen LE, Palmer CV, Pratt S, Erickson KI, Moncrieff D. The effect of decreased audibility on MMSE performance: a measure commonly used for diagnosing dementia. J Am Acad Audiol. 2016;27(4): 311-323.

17. Brickenkamp R. Test d2: Aufmerksamkeits-Belastungs-Test. Göttingen: Hogrefe Verl. für Psychologie; 1962.
18. Bates ME, Lemay EP Jr. The d2 Test of attention: construct validity and extensions in scoring techniques. J Int Neuropsychol Soc. 2004;10(3): 392-400.

19. Helmstaedter C, Lendt M, Lux S. Verbaler Lern- und Merkfähigkeitstest: VLMT; Manual. Göttingen: Beltz-Test; 2001.

20. Lezak MD. Neuropsychological assessment. New York, NY: Oxford University Press; 2004.

21. Kirchner WK. Age differences in short-term retention of rapidly changing information. J Exp Psychol. 1958;55(4):352-358.

22. Wild-Wall N, Falkenstein M, Gajewski PD. Age-related differences in working memory performance in a 2-back task. Front Psychol. 2011; 186(2):1-12.

23. Eriksen BA, Eriksen CW. Effects of noise letters upon the identification of a target letter in a nonsearch task. Atten Percept Psychophy. 1974; 16(1):143-149.

24. Wild-Wall N, Falkenstein M, Hohnsbein J. Flanker interference in young and older participants as reflected in event-related potentials. Brain Res. 2008;1211:72-84.

25. Turner ML, Engle RW. Is working memory capacity task dependent? J Mem Lang. 1989;28(2):127-154.

26. Conway MA. Memory and the self. J Mem Lang. 2005;53(4): 594-628.

27. Reitan RM. Validity of the Trail Making Test as an indicator of organic brain damage. Percept Mot Skills. 1958;8(3):271-276.

28. Sanchez-Cubillo I, Perianez JA, Adrover-Roig D, et al. Construct validity of the Trail Making Test: role of task-switching, working memory, inhibition/interference control, and visuomotor abilities. J Int Neuropsychol Soc. 2009;15(3):438-450.

29. Thurstone LL. Primary mental abilities. Science. 1948;108(2813):585.

30. Rende B, Ramsberger G, Miyake A. Commonalities and differences in the working memory components underlying letter and category fluency tasks: a dual-task investigation. Neuropsychology. 2002;16(3): 309-321.

31. Lehrl S. Manualzum MWT-B: [Mehrfachwahl-Wortschatz-Intelligenztest]. 5, unveränd. Aufl. Balingen: Spitta-Verl; 2005.

32. Yesavage JA, Brink TL, Rose TL, et al. Development and validation of a geriatric depression screening scale: a preliminary report. J Psychiatr Res. 1983;17(1):37-49.

33. Pichora-Fuller KM, Kramer SE, Eckert MA, Edwards B. Hearing impairment and cognitive energy: the framework for understanding effortful listening (FUEL). Ear Hear. 2016;37(suppl 1):5S-27S.

34. Wingfield A, Peelle JE. How does hearing loss affect the brain? Aging Health. 2012;8(2):107-109.

35. Diamond A. Executive functions. Annu Rev Psychol. 2013;64:135-168.

36. Oberauer K, Süß H-M, Wilhelm O, Wittman WW. The multiple faces of working memory: storage, processing, supervision, and coordination. Intelligence. 2003;31(2):167-193.

37. Ronnberg J, Lunner T, Zekveld A, et al. The ease of language understanding (ELU) model: theoretical, empirical, and clinical advances. Front Syst Neurosci. 2013;7:31.

38. Mishra S, Stenfelt S, Lunner T, Ronnberg J, Rudner M. Cognitive spare capacity in older adults with hearing loss. Front Aging Neurosci. 2014;6:96.

39. Meister H, Schreitmuller S, Grugel L, et al. Cognitive resources related to speech recognition with a competing talker in young and older listeners. Neuroscience. 2013;232:74-82.

40. Akeroyd MA. Are individual differences in speech reception related to individual differences in cognitive ability? A survey of twenty experimental studies with normal and hearing-impaired adults. Int $J$ Audiol. 2008;47(suppl 2):S53-S71.

41. Dobbs AR, Rule BG. Adult age differences in working memory. Psychol Aging. 1989;4(4):500-503.

42. Fullgrabe C, Rosen S. On the (un)importance of working memory in speech-in-noise processing for listeners with normal hearing thresholds. Front Psychol. 2016;7:1268.

43. Redick TS, Lindsey DRB. Complex span and n-back measures of working memory: a meta-analysis. Psychon Bull Rev. 2013;20(6):1102-1113. 
44. Tun PA, Williams VA, Small BJ, Hafter ER. The effects of aging on auditory processing and cognition. Am J Audiol. 2012;21(2):344-350.

45. Ellis RJ, Molander P, Ronnberg J, Lyxell B, Andersson G, Lunner T. Predicting speech-in-noise recognition from performance on the Trail Making Test: results from a Large-Scale Internet Study. Ear Hear. 2016; 37(1):73-79.

46. Baddeley AD, Hitch GJ. Working memory. Psychol Learn Motiv. 1974; 8:47-89.

47. Classon E, Löfkvist U, Rudner M, Rönnberg J. Verbal fluency in adults with postlingually acquired hearing impairment. Speech Lang Hear. 2014;17(2):88-100.

48. Rudner M, Ronnberg J, Lunner T. Working memory supports listening in noise for persons with hearing impairment. $J$ Am Acad Audiol. 2011;22(3):156-167.

49. Weiss EM, Ragland JD, Brensinger CM, Bilker WB, Deisenhammer EA, Delazer M. Sex differences in clustering and switching in verbal fluency tasks. J Int Neuropsychol Soc. 2006;12(4):9.

50. Laws KR, Irvine K, Gale TM. Sex differences in cognitive impairment in Alzheimer's disease. World J Psychiatr. 2016;6(1):54-65.

51. Heywood R, Gao Q, Nyunt MSZ, et al. Hearing loss and risk of mild cognitive impairment and dementia: findings from the Singapore Longitudinal Ageing Study. Dement Geriatr Cogn Disord. 2017; 43(5-6):259-268.

52. Lin FR, Yaffe K, Xia J, et al. Health ABC Study Group. Hearing loss and cognitive decline in older adults. JAMA Intern Med. 2013; 173(4):293-299.

53. van Boxtel MP, van Beijsterveldt CE, Houx PJ, Anteunis LJ, Metsemakers JF, Jolles J. Mild hearing impairment can reduce verbal memory performance in a healthy adult population. J Clin Exp Neuropsychol. 2000;22(1):147-154.

54. Lin FR. Hearing loss and cognition among older adults in the United States. J Gerontol A Biol Sci Med Sci. 2011;66(10):1131-1136.

55. Verhaegen $\mathrm{C}$, Collette $\mathrm{F}$, Majerus $\mathrm{S}$. The impact of aging and hearing status on verbal short-term memory. Neuropsychol Dev Cogn B Aging Neuropsychol Cogn. 2014;21(4):464-482.

56. Moafmashhadi P, Koski L. Limitations for interpreting failure on individual subtests of the Montreal Cognitive Assessment. $J$ Geriatr Psychiatry Neurol. 2013;26(1):19-28.

57. Fazeli PL, Ross LA, Vance DE, Ball K. The relationship between computer experience and computerized cognitive test performance among older adults. J Gerontol B. 2013;68(3):337-346.

58. Collerton J, Collerton D, Arai Y, et al. Newcastle 85+ Study Core Team. A comparison of computerized and pencil-and-paper tasks in assessing cognitive function in community-dwelling older people in the Newcastle 85+ Pilot Study. J Am Geriatr Soc. 2007;55(10):1630-1635.

59. Lagana L. Enhancing the attitudes and self-efficacy of older adults toward computers and the internet: results of a Pilot Study. Educ Gerontol. 2008;34(9):831.
60. Miller KM, Price CC, Okun MS, Montijo H, Bowers D. Is the n-back task a valid neuropsychological measure for assessing working memory? Arch Clin Neuropsychol. 2009;24(7):711-717.

61. Lunner T. Cognitive function in relation to hearing aid use. Int J Audiol. 2003;42(suppl 1):49-58.

62. Pichora-Fuller MK, Singh G. Effects of age on auditory and cognitive processing: implications for hearing aid fitting and audiologic rehabilitation. Trends Amplif. 2006;10(1):29-59.

63. Castiglione A, Benatti A, Velardita C, et al. Aging, cognitive decline and hearing loss: effects of auditory rehabilitation and training with hearing aids and cochlear implants on cognitive function and depression among older adults. Audiol Neurootol. 2016;21(suppl 1):21-28.

64. Kalluri S, Humes LE. Hearing technology and cognition. Am J Audiol. 2012;21(2):338-343.

65. Dawes P, Cruickshanks KJ, Fischer ME, Klein BEK, Klein R, Nondahl DM. Hearing-aid use and long-term health outcomes: hearing handicap, mental health, social engagement, cognitive function, physical health, and mortality. Int J Audiol. 2015;54(11):838-844.

66. Dawes P, Emsley R, Cruickshanks KJ, et al. Hearing loss and cognition: the role of hearing AIDS, social isolation and depression. PLoS One. 2015;10(3):e0119616.

67. Cosetti MK, Pinkston JB, Flores JM, et al. Neurocognitive testing and cochlear implantation: insights into performance in older adults. Clin Interv Aging. 2016;11:603-613.

68. Mosnier I, Bebear J-P, Marx M, et al. Improvement of cognitive function after cochlear implantation in elderly patients. JAMA Otolaryngol Head Neck Surg. 2015;141(5):442-450.

69. Giroud N, Lemke U, Reich P, Matthes KL, Meyer M. Longitudinal auditory learning facilitates auditory cognition as revealed by microstate analysis. Biol Psychol. 2017;123:25-36.

70. Anderson S, White-Schwoch T, Choi HJ, Kraus N. Training changes processing of speech cues in older adults with hearing loss. Front Syst Neurosci. 2013;7:2-9.

71. Ferguson MA, Henshaw H. Auditory training can improve working memory, attention, and communication in adverse conditions for adults with hearing loss. Front Psychol. 2015;6:556.

72. Ferguson M, Henshaw H. How does auditory training work? Joined-up thinking and listening. Semin Hear. 2015;36(4):237-249.

73. Morris JC, Heyman A, Mohs RC, et al. The consortium to establish a registry for Alzheimer's disease (CERAD). Part I. Clinical and neuropsychological assessment of Alzheimer's disease. Neurology. 1989;39(9):1159-1165.

74. Lin FR, Metter EJ, O'Brien RJ, Resnick SM, Zonderman AB, Ferrucci L. Hearing loss and incident dementia. Arch Neurol. 2011;68(2): 214-220.

\section{Dovepress}

\section{Publish your work in this journal}

Clinical Interventions in Aging is an international, peer-reviewed journal focusing on evidence-based reports on the value or lack thereof of treatments intended to prevent or delay the onset of maladaptive correlates of aging in human beings. This journal is indexed on PubMed Central, MedLine,
CAS, Scopus and the Elsevier Bibliographic databases. The manuscript management system is completely online and includes a very quick and fair peer-review system, which is all easy to use. Visit http://www.dovepress. com/testimonials.php to read real quotes from published authors. 